\title{
The Challenges of Existing Syntactic Models for English Language Teaching and Learning in Nigeria
}

\author{
Roseline Abonego Adejare ${ }^{1, *}$ \\ ${ }^{1}$ Department of Language, Arts and Social Science Education, Lagos State University, PMB 0001, LASU Post Office, \\ Badagry Expressway, Ojo, Lagos, Nigeria \\ *Correspondence: Department of Language, Arts and Social Science Education, Lagos State University, PMB 0001, \\ LASU Post Office, Badagry Expressway, Ojo, Lagos, Nigeria. E-mail: abonego@yahoo.com
}

$\begin{array}{ll}\text { Received: July 29, } 2019 & \text { Accepted: September 24, } 2019 \quad \text { Online Published: November 11, } 2019 \\ \text { doi:10.5430/ijelt.v7n1p1 } & \text { URL: https://doi.org/10.5430/ijelt.v7n1p1 }\end{array}$

\begin{abstract}
A recent survey of existing syntactic models shows that none accurately describes the syntax of the English language that people actually use and that they inhibit rather than promote knowledge of natural language by creating a gap between what should be taught and learned and what obtains. To demonstrate this gap, this paper critically examines four recommended senior secondary school English course books to determine the extent to which they reflect existing syntactic models' descriptive inadequacies, and highlights the implications for language education in Nigeria. Using the emerging Natural Language Linguistics (NLL) model as analytical tool, each book was carefully examined to identify topics on the syntactic units: sentence, clause and group. These were then critically studied, paying great attention to definitions, descriptive statements, models, and examples, and noting common features and differences. The bits of information pieced together constitute the data. Findings show inconsistency in model application, no uniformity in, and consensus on, the number and nomenclature of syntactic units, terminological confusion, descriptive inaccuracies, typological inexactness, incorrect definitions, wrong and inappropriate examples, and confusion between constituents and elements of structure. The absence of a clear-cut distinction between phrase and clause and between clause and sentence in existing syntactic models, which reflected in the books, explains the shortcomings that potentially limit learners' knowledge and use ability. Only a syntactic model that accurately mirrors natural language structure can positively promote language education in the Nigerian context where course books are the most important English teaching-learning resource.
\end{abstract}

Keywords: syntactic models, syntactic units, English course books, textbook evaluation

\section{Introduction}

Education is vital for language acquisition and language use, whether in a formal or an informal setting. Whereas L1 acquisition is taken for granted because it is seen as a part of the normal developmental process, L2 acquisition presents a different ball game altogether. The processes, situations, conditions, and experiences are so markedly different that the term English as Teacher Tongue (ETT) is aptly used, in an apparent analogy with English as a Mother Tongue (EMT), for English language learning in a non-native environment. Here, the learner looks up to the teacher as model, and both parties concomitantly rely almost entirely on what may be regarded as the most invaluable resource material: the recommended English course book. Given this scenario, one would expect that existing English syntactic models would provide an accurate picture of the structure of the English language that people actually use to ensure proper acquisition and subsequent correct usage. Unfortunately, a critical look at existing syntactic models has shown that they inhibit knowledge of the language rather than promote it: They are derived from Saussure's (1916) 'form is the norm' doctrine for linguistics, which 20th Century linguists translate to 'language is form', instead of form and situation. No syntactic model today accurately describes the syntax of the English language. This has been demonstrated by a survey of the three major descriptive models that now circulate in the world, namely Chomsky's Transformational Generative Grammar (TG), Quirk et al.'s Neo-Traditional Grammar (NTG), and Halliday's Systemic Grammar (SG), including the latest attempt to enhance it, Functional Grammar 
(FG). It has been proven that some linguists invent the language they describe instead of the structure of the actual language that people use (Adejare, 1990; forthcoming).

This paper therefore takes off from Adejare's evaluative work that culminated in his Natural Language Linguistics (NLL) model which empirically confirms form and situation as the elements of language structure. It argues that because none of the three major syntactic models accurately describes the syntax of the English language that people actually use there is a serious gap between what should be taught and learned in English syntax and what actually obtains in practice. To prove the existence of this gap, the paper critically examines popular English course books in use in Nigeria's senior secondary schools with a view to determining the extent to which they reflect the identified descriptive inadequacies of existing syntactic models. It also highlights the implications for language education in the Nigerian ESL situation.

The choice of course books is underscored by the high degree of dependence that both the teacher and the learner of English are known to have on the resource material in the teaching-learning endeavour. Since they are written in strict adherence to the approved English curriculum for senior secondary schools, examining the curriculum and /or observing lessons in addition would be superfluous and ineffectual. English textbooks are not known to have been evaluated from the perspective of the syntactic models that fundamentally inform them. For instance, Thuy-Minh (2015) based her evaluation on methodology and practicality while Mukundan et al. (2011) and Lopez-Medina (2016) developed check-lists that exclude the syntactic models as evaluative criteria. Results of this analysis are therefore expected to significantly change the general perception of the sources of L2 acquisition problems, including how they are diagnosed and analysed.

Immediately after this introduction is the presentation of the challenges posed. It is followed by a condensed version of the syntactic models' evaluation in order for the essence of the current arguments, which themselves derive their theoretical and descriptive statements there from, to be brought into proper perspective, an account of the research method, a detailed analysis of the syntactic contents of the selected course books, summary of observations, and conclusion in that order. The rest of the paper proceeds as follows.

\section{The Challenges}

When existing syntactic models are viewed in relation to the Standard English norm that we want to teach in schools, it would be discovered that a high amount of syntactic structures are excluded or misrepresented. This limits what pupils can know and what they can do with their language. This section therefore identifies some of the challenges posed by the use of inaccurate descriptive models.

The poor standard of English language teaching in Nigerian schools has often been traced to defects in the English degree programmes typified by the language/literature quagmire (Mohmed, 1976; Bamgbose, 1991; Adejare, 1984), content/methodology imbalance (Abe, 1984), and unmet graduation requirements for English relative to Education by as high as 47 percent (Adejare, 2003). Even the little grammar that teachers-to-be are exposed to is faulty because of model deficiency: The minimal syntax is packaged in inaccurate theoretical and descriptive moulds. Poor training results in poor teaching and poor usage. A poorly trained English graduate will encounter great difficulty teaching the language, and will be unable to recognise and rectify errors in English course books where they manifest. So critical is the problem that Mohmed (1976) called for immediate embrace of the right linguistic techniques for effectiveness. Although he was motivated by the then burning issue of literature/language imbalance, which produced teachers who were unable to teach English grammar because of poor knowledge, it is sad that no syntactic model today can give the trainee English teacher and prospective course book writer the desired 'deeper insight into the workings of the language'. So, the situation of teacher quality has not changed.

At a recent professorial interview in a Nigerian university, a panellist was reported to have questioned a candidate's preference for grammatical research, wondering its relevance. They added boastfully that they consider themselves one of the best users of English in Nigeria and that the 'syntax' they were taught at the undergraduate level did not contribute to their ability and skill (The referent had a TG background and has veered off language studies completely). This confirms the hopelessness of existing syntactic models in achieving descriptive accuracy with respect to the English that people actually use. Syntactic models' inaccuracy could also explain why most linguists in this part of the world avoid grammatical research like a plague. Indeed, for such scholars, a doctorate in English Language means sociolinguistics, pragmatics, stylistics, discourse analysis, and applied English linguistics. (These sub-disciplines require little or no rigorous syntactic analysis.) Grammatical research is worth the while if the 
analytical tools are right, which means they can provide fresh insights into the structure of the actual language that people use.

\section{The Evaluated Syntactic Theories and Syntactic Models}

Since the theoretical arguments of this paper derive from the outcome of Adejare's (1990; forthcoming) critical review of the three syntactic models, it becomes expedient to present summarily how the conclusions were arrived at. This section also details the emerging Natural Language Linguistics (NLL) model.

\subsection{Syntactic Theories}

What exists as linguistic theories today are actually syntactic theories wrongly equated with the former, following Saussure's (1916) linguistic atomism whose language is 'a form, not a substance' doctrine excludes not only phonology and graphology from linguistics but also situation. Hjelmslev's (1943) theory, which was deductive in intent and which was initially conceived as a natural language text theory, embraced total atomism and fragmented 'text' into a syntactic form that lacks semantics. The absence of semantics and phonetics obviously excludes ideational meaning, phonology and even syntax, which makes it more atomistic than Saussure's theory. It is this 'atomism that has put text under a heavy intellectual fog' till today (Adejare, forthcoming).

Although Chomsky (1965) invaluably actualised Hjelmslev's transformational rules and linguistic algebra, like Saussure, he made atomistic linguistic proper TG's template and invented an artificial language for TG to study. He writes:

Linguistic theory is concerned primarily with an ideal native speaker-listener, in a completely homogeneous speech-community, who knows its language perfectly and is unaffected by such grammatically irrelevant conditions as memory limitations, distractions, shifts in attention and interest, and errors (random and characteristic) in applying his knowledge of the language in actual performance. (Emphasis added)

This is faulted on the following grounds: No ideal text coder exists since all coders edit their texts; a completely homogeneous speech-community is a fiction because a speech-community is heterogeneous; the attribution of perfect linguistic knowledge to the fictional speaker-listener is wrong; memory limitations are relevant for text-coding; and, distractions are natural in world structure event coding. Moreover, 'applying his knowledge in actual performance' is inherently contradictory because the ideal speaker-listener lacks human traits and unique codes to do so. TG's idealisation, made possible by the excision of situation, represents total atomism. That makes it a syntactic, not a linguistic, theory.

Although Firth (1957) envisioned Saussure's (1916) recognised, but rejected, holistic linguistics of speaking, he validated his theory with only minimal data. Halliday's (1961) SG model espoused Firth's holism in its recognition of form and situation as language structure elements. It includes more language elements (SUBSTANCE, FORM, and PHONOLOGY) and attaches situation to CONTEXT. SG is a more accurate syntactic model than its rivals on this account. However, it excludes situation from its linguistics and wrongly separates PHONETICS from LINGUISTICS (Halliday et al., 1964). Moreover, its core of linguistics is LEXIS and GRAMMAR, having excluded text, the largest unit of language. SG is therefore a partial atomistic syntactic theory.

\subsection{Syntactic Models}

Atomism masks syntactic theories as linguistic theories. This produces inaccurate analysis of syntax and leads to two forms of errors, namely 'language-is-form error' and 'each-model-its-form error'. FORM varies from model to model and is thus imprecise. Whereas all models from Saussure's to Halliday's exclude phonology from FORM, phonology is alloyed with grammar to create FORM and even has syntactic functions. Furthermore, data from aphasic and schizophrenic patients prove that situation is an element of language structure and that while aphasia only distorts lexical and syntactic units (FORM), schizophrenia is marked by inability to code reality, which impairs a text's SITUATION coding. The each-model-its-syntax error produces conflicting number of syntactic units, elements of clause structure, and structural formulae, which are themselves sources of inaccuracy in syntactic analysis, with great challenges for students of linguistics (Adejare, 1990; forthcoming). The syntactic units were evaluated separately to determine each model's descriptive accuracy.

\subsubsection{Syntactic Units}

Resulting from the each-model-its-syntax error are two competing sets of four and five units of syntax that have no agreement on what lies between SENTENCE and WORD, as Table 1 shows (Adejare,1990; forthcoming). 
Table 1. Conflicting Syntactic Units

\begin{tabular}{ll}
\hline TG & SG \\
\hline & SENTENCE \\
SENTENCE & CLAUSE \\
PHRASE & GROUP \\
WORD & WORD \\
MORPHEME & MORPHEME \\
\hline
\end{tabular}

Using 'The drums beat, the flutes sang and the spectators held their breaths expectantly', a sentence taken from Chinua Achebe's Things Fall Apart, it was proved that phrase is inaccurate as a syntactic category (Quirk et al., 1985; Halliday \&Matthiessen, 2004; Radford, 2004) and that it is not equivalent to clause or group. Furthermore, TG's four-unit syntax misrepresents English syntactic units while SG's five units more accurately represent them. This establishes the syntactic units of English as sentence, clause, group, word and morpheme.

\subsubsection{Elements of Clause Structure and Structural Formulae}

Beginning with the sentence, TG 's two-element structure depicted as $\mathrm{S} \longrightarrow \mathrm{NP}+\mathrm{VP}$ is a misrepresentation, whereas $\left(\beta^{(0-n)}\right) \alpha^{(1-n)}\left(\beta^{(0-n)}\right.$, which recognises obligatory (alpha) and optional (beta) elements of sentence structure and which generates the three sentence types of simple, compound and complex (Adejare \& Adejare. 2006), more accurately represents the English sentence. Because most models do not recognise the clause as a syntactic unit, its description is inevitably inaccurate, with discrepancies in the number of clause structure elements and consequently clause structure formulae:

(a) Subject and Predicate: S+P (Traditional Grammar) (Jespersen, 1933; Christophersen \& Sandved, 1969)

(b) Noun Phrase and Verb Phrase: S $\longrightarrow$ NP +VP (TG) (Chomsky, 1965)

(c) Subject, Predicator, Complement and Adjunct: (S) P (C) (A) (SG) (Halliday, 1961)

(d) Subject, Verb, Object Complement and Adverbial: S+V+O+C+A (NTG) (Quirk et al., 1985)

These formulae are focused on affirmative clauses, but SG can also analyse some imperative clauses.

An objective criterion, comprising the functions of form and situation (both determinants of clause structure elements) and validated with data, was set up to determine which of the four formulae adequately represents the English coder's knowledge of the clause. It revealed that whereas SG meets one criterion because it recognises only formal micro functions (actor, process, goal and circumstance) and not textual macro functions, TG recognises none because function for it is just a metalanguage. NTG vaguely recognises formal function as 'a unit's privilege of occurrence' (Quirk et al., 1985). This revelation establishes the fact that the absence of situation accounts for descriptive inaccuracy and makes the derivation of a situation-induced clause structure formula that will enhance the descriptive accuracy of the (S) P (C) (A) formula imperative. A new formula that integrates multiplicity, mobility and inversion of elements of clause structure (Adejare \& Adejare, 2006) and that describes all naturally occurring major and minor clauses was subsequently derived.

\subsection{Evaluation of Existing Clause Structure Formulae}

The NLL model in 3.4 below was the criterion used in evaluating the three existing clause structure formulae presented as follows.

\subsubsection{TG's $\longrightarrow$ NP + VP Formula}

TG's adoption of Traditional Grammar's four-scale-grammatical units in which the sentence and clause are not distinguished, whereas these are clearly distinguished in normal language structure, produced its very inaccurate $\mathrm{S}$

$\longrightarrow \mathrm{NP}+\mathrm{VP}$ formula. It cannot analyse a sentence of more than one clause (e.g., 'The drums beat, the flutes sang and the spectators held their breaths expectantly'), inversion-coded interrogative clauses (e.g. How do you do?), imperative clauses that generally lack subjects (e.g., Bring the books), and minor clauses(e.g., 'Fine', response to the routine question 'How are you today?). The formula can accurately analyse some two-element affirmative clauses (e.g., 'The drums beat'), but it cannot handle clauses with more than two elements or those involving mobility (e.g., Expectantly the spectators held their breaths). TG's failure to accurately analyse most sentences and clauses is 
because its language-is-form error lacks structure-determining formal and functional functions. Atomism thus limits its descriptive accuracy of actual sentences.

\subsubsection{NTG'sS+V+O+C+A Formula}

NTG 's clause structure formula that mixes traditional and modern categories poorly distinguishes sentence from clause and 'stunningly' assigns, inaccurately, obligatory status to all its elements despite recognising optionality (Quirk et al., 1985). It makes the word class verb an element of clause structure, confusing and mixing clause structure element (Predicator) with word class element (verb). It mishandles multiplicity by making object a distinct element of clause structure. Indeed, its third sloth ' $\mathrm{O}$ ' is an imprecise traditional category since both nominals and adjectives follow the verb. Although the formula generates several affirmative clauses, inversion that generates interrogative clauses is unrepresented. Moreover, its uncoded mobility and optionality limit its coverage and its capacity to analyse subjectless imperative clauses.

\subsubsection{SG's (S)P(C)(A) Formula}

Because it is based on Firth's idea that one must analyse the language that people actually use, SG's formula more accurately analyses many more clauses than its rivals. The (S)P(C)(A) formula recognises an obligatory $\mathrm{P}$ and optional S, C and A as elements of clause structure, which means it can more accurately analyse most affirmative and imperative clauses. However, the formula cannot accurately analyse affirmative clauses involving multiplicity (e.g. ||The plateau |is |flat,| very fertile| and cool.||), mobility (e.g., ||Expectantly| the spectators |held |their breaths|.), and inversion (e. g, \|[ [[ am very happy]],| said |John.||) of elements of clause structure. Also because of non-recognition of situation-induced inversion the formula cannot accurately analyse interrogative clauses generally (e.g., || $\mathrm{How}|\mathrm{do}|$ you| do? |). So, SG's formal function-derived formula fails to analyse interrogative clauses and all clauses with multiple, mobile and inverted elements of structure because situation is not part of its linguistics.

\subsection{The Clause Structure Formula of Natural Language Linguistics (NLL)}

The clause structure formula of Natural Language Linguistics (NLL) (Adejare, forthcoming) is based on the theoretical proof that FORM and SITUATION are the twin obligatory elements of language and must be integrated in the analysis of natural language elements. So, it is a text-function derived clause structure formula represented thus:

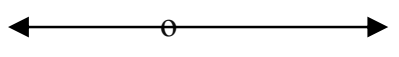

$$
\text { (S) } \mathrm{P}\left(\mathrm{C}^{(\mathrm{mu})}\right)\left(\mathrm{A}^{(\mathrm{mu}, \mathrm{mo})}\right)
$$

This enhanced SG's (S)P(C)(A) structural formula would address most, if not all, the inadequacies of SG, adjudged the most accurate among its competitors. It takes SG's five-unit syntax and four-element clause structure as given, and recognises and integrates situation as evident in the superscripts $\left(\mathrm{C}^{(\mathrm{mu})}\right)$ and $\left(\mathrm{A}^{(\mathrm{mu}, \mathrm{mo})}\right)$. The top two-directional arrow lying across point $o$ signals that inversion may or may not be present and that each element of structure can move either left or right. This adequately takes care of multiplicity, mobility and inversion and shows that all naturally occurring major and minor English clauses can be accurately analysed. The NLL formula, which finds theoretical parallel in Harris' (1990) radical/total integrationism, therefore resolves the problem of atomism that has plagued linguistics since the dawn of the 20th Century. We subscribe to this view of language and will adopt it with its formula for this work.

\section{The Method}

\subsection{Data Base}

Two English course book series and one non-serial English course book were selected on the basis of their popularity among teachers and pupils in schools in Lagos State, Nigeria where this research was conducted. The decision on which of Books 1-3 to choose in the two series was guided by their grammatical contents. Thus the following four books were selected.

(a) Senior English Project for Secondary Schools: Students' Book 1 (SEP1)(Grant, Nnamonu \& Jowitt, 2011)

(b) Goodbye to Failure in English for Senior Secondary Schools: Students' Books 1 (GFE1) (Mebele \& Omodara, 2018)

(c) Goodbye to Failure in English for Senior Secondary Schools: Students' Books 3 (GFE3) (Mebele \& Omodara, 2006) 
(d) Essential English Language for Senior Secondary Schools (EEL) (Latilo\& Beckley, 2008)

\subsection{Data Collection}

Each book's table of contents was carefully examined to find out whether or not it contains presentation on the syntactic units sentence, clause and group. The relevant pages were then opened to and critically studied, with great attention paid to definitions (where available), descriptive statements (where present) and their accuracy, overt indication of descriptive models, examples (their correctness and appropriateness), and practice exercises (where available). Notes were taken and features were compared and contrasted. All the identified pieces of information on the sentence, clause and group constitute this study's data.

\subsection{Data Analysis}

The emerging Natural Language Linguistics (NLL) model is the syntactic model of choice as already hinted. The data was categorised into three major subsets based on the NLL model's recognised three largest syntactic units of sentence, clause and group. Each syntactic unit was exhaustively described as contained in the textbooks. Copious examples of a syntactic unit under consideration (or aspects thereof) were identified and extracted from the relevant sections of the books manifesting them to support the claims made. The syntactic structures were linearly analysed, with some simply listed and commented upon as appropriate. Tables were utilised for their compactness and vividness while simple percentage aided the essentially syntactic analysis.

\section{Presentation and Discussion of Findings}

This section presents and discusses the results of the critical examination of the four selected English course books aimed at determining the degree to which they reflect the descriptive inadequacies of existing syntactic models, among others. NLL's three largest syntactic units of sentence, clause and group form its major divisions. Where copious examples are cited, the source texts and page references are supplied appropriately. Erroneous examples are asterisked while structures under focus are italicised. It begins with the group.

\subsection{The Group}

The median syntactic unit group is named phrase in the books whereas the descriptive term phrase is problematic as seen above. The definitions of phrase found, its subtypes, and examples cited are as exposed in Table 2 below. As it shows, a number of problems have arisen because phrase does not describe a unit of syntactic structure, which is the sentence, clause, group, word or morpheme. Borrowed from Traditional Grammar as a way of tackling the division of the clause erroneously called sentence into subject and predicate, the inaccurate term creates more confusion in language learning and language teaching. This is best examined systematically under the same apt headings as in Table 2.

\subsubsection{Definitions}

Though the expression 'a group of words' recurs in the definitions of phrase quoted (SEP1 does not define phrase but treats noun phrase in connection with determiners and functions, e.g., pp. $22 \& 43$ ), there are divergent views on whether the phrase makes sense at all or makes incomplete sense. This notional definition is bound to confuse the learner and even the teacher. EEL defines phrase as a constituent of the sentence. This exposes the error inherent in the four-unit and five-unit models that do not properly distinguish sentence and clause or recognise group as the more descriptively accurate unit between clause and word on the grammatical rankscale. Only clauses constitute sentence structure; groups do not directly enter into sentence structure.

Two aspects of GFE3's definition deserve attention. First, since the phrase lacks 'a subject and a predicate', its elements of structure should have been identified in order to bring the structural definition into its full circle. But this is not possible because, unlike group, phrase does not have an organic composite structure. Second, 'functions as a single part of speech', is an imprecise and incorrect statement deeply rooted in Traditional Grammar, as Halliday (1985) explains:

In the European linguistic tradition, classes were originally derived from an analysis of sentence into parts; the term 'parts of speech 'is a mistranslation of the Greek meroi logou, Latin partes orationis, which actually meant 'parts of a sentence'. The 'parts of a sentence', which began with Plato (or before him) not as classes but as functions, were subsequently elaborated into a scheme of word classes, established on the basis of different inflectional potential that different words had in Classical Greek. 
Table 2. Definitions, Subtypes and Examples of Phrase

\begin{tabular}{|c|c|c|c|}
\hline Books & Definitions & Types & Examples \\
\hline \multirow{7}{*}{$\begin{array}{l}\text { EEL, } \\
\text { pp.77-80 }\end{array}$} & \multirow{7}{*}{$\begin{array}{l}\text { 'the phrase can be } \\
\text { defined as a group of } \\
\text { words that does not } \\
\text { make sense and which } \\
\text { only forms part of a } \\
\text { sentence' }\end{array}$} & Noun Phrase & (a)I saw the village headmaster. \\
\hline & & & *(b) To sleep without light is frightening \\
\hline & & Adjectival & *(a) The man standing at the gate is my father. \\
\hline & & Phrase & $\begin{array}{l}*(\text { b) The student to be suspended has stopped coming to } \\
\text { school, }\end{array}$ \\
\hline & & Adverbial & *(a) I put the food on the table \\
\hline & & Phrase & *(b) The student comes to school twice a week. \\
\hline & & & (c) He studies hard in order to pass. \\
\hline \multirow{5}{*}{$\begin{array}{l}\text { GFE1, } \\
\text { pp.83-84 }\end{array}$} & \multirow{5}{*}{$\begin{array}{l}\text { 'A phrase refers to a } \\
\text { group of words which } \\
\text { does not express } \\
\text { a complete thought' }\end{array}$} & Noun Phrase & A car, a new car, a little new car, a little new Japanese car \\
\hline & & Adjective & (a)That man in red shirt slapped a girl. \\
\hline & & Phrase & (b)Adauje is a girl of great honour. \\
\hline & & Adverb Phrase & (a)The driver drove without any care. \\
\hline & & & (b) He spoke to the teacher in a very polite manner. \\
\hline \multirow{24}{*}{$\begin{array}{l}\text { GFE3, } \\
\text { pp.109-12 } \\
6\end{array}$} & \multirow{24}{*}{$\begin{array}{l}\text { In grammar, a phrase is } \\
\text { a group of words } \\
\text { without a subject and a } \\
\text { predicate, that functions } \\
\text { as a single part of } \\
\text { speech' }\end{array}$} & Noun Phrase & (a)A friend of mine was here a few hours ago. \\
\hline & & & (b)Mr Ajana punished the best boy of my class. \\
\hline & & Prepositional & (a)I walked down the winding road. \\
\hline & & Phrase & (b)The people were singing on the bus. \\
\hline & & Adverb Phrase & (a)The engineer constructed the car with great skill. \\
\hline & & & (b)The boy was found after a long search. \\
\hline & & & (c)Tell the story in your own words. \\
\hline & & & (d) I'll be there no matter how difficult. \\
\hline & & Adjective & (a)Dauda is a beggar with a limp. \\
\hline & & Phrase & (b) The house next to us is Ola's. \\
\hline & & & (c) She was pure in heart. \\
\hline & & & (d) He is slow in speech. \\
\hline & & Participial & (a)Looking up suddenly, Lola saw a rainbow in the sky. \\
\hline & & Phrase & (b) The house, renovated recently, is very attractive. \\
\hline & & Gerund Phrase & (a)Going home late is risky. \\
\hline & & & (b) I shall adopt visiting her often. \\
\hline & & & (c) John was afraid of being cheated. \\
\hline & & Infinitive Phrase & (a)We shall go to Ibadan to collect our results. (b)Her attire \\
\hline & & & seemed to express the attitude of her spirit. \\
\hline & & & (a) Akin does eat rice. \\
\hline & & Verb Phrase & (b) He was caught by me. \\
\hline & & & (c) I did not agree to his ideas \\
\hline & & Absolute Phrase & (a)Weather permitting, we shall attend. \\
\hline & & & (b)The game being over, we departed. \\
\hline
\end{tabular}




\subsubsection{Types}

There is no consensus on the types of phrase and the number either. While EEL and GFE 1 recognise three, GFE 3 identifies nine. Although GFE 3 presents a more comprehensive list because it includes VP and PP, there are observable inaccuracies. First, there cannot be nine phrases when there are only five word classes that head groups and after which each group is named. These are noun, verb, adjective, adverb, and preposition and the groups they head are respectively the nominal group (NMG), verbal group (VBG), adjectival group (AJG), adverbial group (ADG), and prepositional group (PRG). Second, it balkanises the VBG, recognising as VP only the finite subtype with an auxiliary verb and wrongly designating the different morphological variants of the non-finite VBG as infinitive phrase, gerund phrase and participial phrase. Moreover, it includes absolute clause, a type of $\mathrm{x}+\mathrm{g}$ or $\mathrm{x}+\mathrm{n}$ non-finite VBG clause or predicator-less clause that functions as adjunct in the clause structure (Quirk et al., 1985), as a type of phrase. These bring into the fore the problems of inaccurate description.

\subsubsection{Examples}

Perhaps it is in exemplification that the errors are more manifestly disturbing, where the non-recognition of these basic facts and confusion between a syntactic form and its function have led to inaccurate descriptive statements and wrong examples. All the five types of group wrongly tagged phrases are adequately illustrated in sentence context, except the NMG in GFE1. Examples of the NMG tagged NP are descriptively accurate, and they include nominalised clauses at S or C. The PRGs wrongly labelled PPs are similarly correctly illustrated. However, examples cited for the VBG, ADG and AJG, respectively mislabelled VP, adjective phrase and adverb (adverbial) phrase, are monumentally erroneous. This point requires expatiation using data.

\section{(a)The Verbal Group}

The balkanisation of the VBG inaccurately described as VP into verb phrase, gerund phrase, infinitive phrase, and participial phrase has already been noted. It has also been seen that only in GFE 3 is this syntactic unit recognised in some form. There are more striking observations. No H-Type VBG is illustrated under VP because of the wrong notion that a phrase consists of 'a group of words'. Indeed, GFE 3 states that 'a verb phrase is formed when one or more auxiliary verbs are combined with a lexical (main or principal) verb' (p.123). This implies that both the auxiliary verb and the lexical verb realise obligatory elements of the VBG structure and that the group, an instance of which the VBG is, lacks optional elements of structure. This descriptive error is accounted for by the use of inaccurate phrase. All the examples cited are MH-Type VBGs (e.g., are being addressed; shall write). No HQ-Type and MHQ-Type VBGs, whether particled or catenated, is seen. The exclusion of these structural variants limits what pupils can formally learn and know about the VBG structure. Interestingly, learners encounter them in comprehension passages and in their everyday language use activities but are denied the opportunity to experience them descriptively.

The so-called gerund phrase, infinitive phrase, and participial phrase have 22 sentential illustrations altogether. Eighteen are syntactically non-finite VBG clauses and are therefore neither VBGs nor phrases in the sense of 'a group of words without a subject and a predicate'. They have the obligatory predicator realised by non-finite-verb-headed VBGs, and function variously as an optional element of structure of the complex sentence (8, e.g. [1] \& [2]) and elements of clause structure (10) as subject (3), complement (2), and adjunct (5). The examples in context are presented below.

[1]|| ( $\beta$ ) Coming close to the rock, || ( $\alpha$ ) Bada was a strange sight|||

[2]|| ( $\beta$ ) Caught red-handed, || $(\alpha)$ he seemed obviously guilty ||

$$
\begin{array}{llll}
\mathrm{S} & \mathrm{P} & \mathrm{C} & \mathrm{A}
\end{array}
$$

[3]|| [[Forgetting her]] |is | the solution | to your problem||

$$
\mathrm{S} \quad \mathrm{P} \quad \mathrm{C}
$$

[4]||The only thing to do| is |[[calling them again]]||

$\begin{array}{llll}\mathrm{S} & \mathrm{P} & \mathrm{A} 1 & \mathrm{~A} 2\end{array}$

[5] || She |went| into the shop |[[to buy a pen $]] \|$

To prove that they are clauses and not groups or even phrases, each one is pulled out and analysed into its elements of clause structure as [6a-6e] respectively. The VBGs in predicator function are italicised.
$\mathrm{P}$
A1
$\mathrm{A} 2$
$\mathrm{P}$
$\mathrm{C}$ 
[6a] $\|(\beta)$ Coming |close |to the rock\|

$\begin{array}{lllllll}\mathrm{P} & \mathrm{C} & \mathrm{P} & \mathrm{C} & \mathrm{A} & \mathrm{P} & \mathrm{C}\end{array}$

$[6 \mathrm{c}] \mid(\beta)$ Forgetting $\mid$ her $\|$

[6d] $\quad \|(\beta)$ calling |them |again $\|$

$[6 \mathrm{e}] \|(\beta)$ to buy |a pen $\|$

There is one correctly described MH-Type to-non-finite VBG functioning as adjunct.

$\begin{array}{llll}\mathrm{S} & \mathrm{P} & \mathrm{C} & \mathrm{A}\end{array}$

[7] ||He |was looking for | a book |to read $\|$

There is however an instance of a catenated HQ-Type finite VBG (seemed to express) in predicator function wrongly illustrated as infinitive. There are two possible explanations for this error. The catenative verb at $\mathrm{H}$ may not have been reckoned with as an integral part of the VBG structure, and the to-non-finite form at Q may have been erroneously believed to be functioning independently. Here is the context.

\section{$\mathrm{S} \quad \mathrm{P} \quad \mathrm{C}$}

[8]||Her attire| seemed to express | the attitude of her spirit.||

Two structures listed as gerunds because of their initial $\mathrm{x}+\mathrm{g}$ forms are, though non-finite VBGs, not 'gerund phrases'. Gerunds are intrinsically $\mathrm{x}+\mathrm{g}$ form lexical verbs whereas these examples feature the non-finite forms of auxiliaries $\mathrm{BE}$ and HAVE, markers of passive voice and perfective aspect respectively. Their description as PRG qualifiers is however in order. Here are the examples, analysed (Notice that [9] is a VBG while [10] is a clause).

[9]||John |was | afraid |of [being cheated] ||

[10] ||My wife |was |proud |of [[having beaten the record]] ||

Not unexpectedly, the subtypes are inaccurately differentiated even in exemplification. For instance, notwithstanding the syntactic similarity between having beaten the record above and having gone home in 'Having gone home, she ate her food and rested' (GFE3 p.121), they are described as gerund phrase and participial phrase respectively, whereas both are non-finite VBG clauses. Nothing can be more confusing and contradictory.

(b) The Adjectival Group

EEL cites only two examples of AJG and both are rankshifted non-finite clauses functioning as qualifier in the NMG structure. In the GFE series, what are cited as AJGs are syntactically PRGs, justified by the grossly erroneous statements: 'an adjective phrase is a prepositional phrase and 'In that case, it is introduced by a preposition' (GFE 3, p.116). In fact, it treats as AJG (adjective phrase) the PRG (PP) paraphrase of the H-Type AJG in modifier function in the NMG structure at $\mathrm{S}$ or $\mathrm{C}$, defines the adjective phrase as 'a group of words without a verb, making incomplete sense and doing the work of an adjective', and adds that it 'is often the equivalent of an adjective' (GFE 3, p.117). A pair of clauses illustrating such 'equivalence' will suffice (No clause with an AJG at C is illustrated probably because it is not paraphrase-able).

[11a] 'Chidi is an intelligent pupil (Adjective)'

[11b] 'Chidi is a pupil with intelligence. (Adjective Phrase)'

The traditional definition of the adjective as a word that qualifies a noun leads to the erroneous belief that any form in a similar syntactic context must be functioning adjectivally and must therefore be an adjective. This portends great danger for young ESL learners who must be forced to accept such wrong notions because they are contained in their course books. To state that an AJG is a PRG, even after correctly identifying structures such as with intelligence as a PRG (PP), because it must be doing 'the same work' as the adjective intelligent, or, that a rankshifted finite or non-finite clause at Q is an AJG because it immediately follows a nominal headword, is a clear demonstration of the dangerous length to which the adoption of inaccurate descriptive models can go to harm and destroy language learning, particularly in an ESL context. Syntactic units must be clearly distinguished from their syntactic functions.

(c) The Adverbial Group

Not one of the 40 sentences purportedly illustrating the adverb (adverbial) phrase in the books is correct. Thirty-two of them are preposition-headed. There is the non-finite VBG clause in adjunct function, first confused as PP because of its initial in, and then equated with an adverbial phrase because of its semantic function. Note that in order to is an 'explicit subordinator of purpose' (Quirk et al., 1985). The sentence is correctly analysed as [12].

$$
\begin{array}{llll}
\mathrm{S} & \mathrm{P} & \mathrm{A} 1 & \mathrm{~A} \text { 2: }
\end{array}
$$

[12] He |studies| hard |[[in order to pass.]]|| 
(cf. 'You must study hard in order not to fail.' GFE 3, p.116)

The second is twice a week, which actually consists of two different groups incorrectly lumped together as one adverbial phrase. These are H-Type ADG (frequency adverb) and MH-Type temporal NMG functioning as adjuncts. The correct analysis displays these facts more convincingly.

$$
\begin{array}{lllll}
\mathrm{S} & \mathrm{P} & \mathrm{A} 1 & \mathrm{~A} 2 & \mathrm{~A} 3
\end{array}
$$

[13] ||The student| comes |to school| twice |a week||

The remaining structures incorrectly illustrated as adverb phrases in GFE 3 (p.116) are:

[14] 'I'll be there no matter how difficult.' (MHQ-Type NMG at A),

[15] 'My father is 'richer than yours. '( $Q$ in HQ-Type AJG at C; than is a subordinating conjunction initiating the 'comparative clause')

[16] 'I shall agree based on her sincere apologies.' ( $\mathrm{x}+\mathrm{n}$ non-finite VBG clause at A)

[17] 'Janet must work hard to pass her exams.' (to-non-finite VBG clause at A2)

$[18]$ *'Tolu is not so tall as Ibitoye'. (MH-Type AJG at C)

As observed earlier with AJG, PRG paraphrases of H-Type ADGs are inaccurately identified as adverb or adverbial phrases and they represent 80 percent of all examples cited. Although adverbs are correctly recognised, it is their PRG equivalents that are considered phrases instead. This ill-description occurred, not only because of the syntactic in-exactitude of the term phrase, but also because of the expression 'group of words' in its standard definition. So, the authors must have reckoned that since the H-Type ADG comprises one adverb lexeme only, it cannot on its own constitute a phrase. So, there has to be two or more words. In contrast, the group as a syntactic unit is made up of one or more words and so poses no descriptive problems.

Another possible reason is metalanguage-related. In NTG, the term adverb (and verb too) serves both as a word class and as an element of clause structure. This mixes lower level metalanguage with higher level metalanguage, which is a major descriptive problem. Consequently, anything that functions as an adverbial (adjunct) is regarded as an adverbial phrase. Consider Table 3 (GFE3, p114) below, where the PRGs to the right, though correct paraphrases of the H-Type ADGs to the left, are wrongly labelled adverbial phrases. (EEF also fails to recognise non-morphologically marked H-Type ADGs as adverbial phrases.)

Table 3. Confusion between Adverbial Phrase and Prepositional Phrase

\begin{tabular}{ll}
\hline ADVERBS & ADVERBIAL PHRASES \\
\hline The engineer constructed the car skilfully. & The engineer constructed the car with skill. \\
She won the context fairly & She won the context by fair means. \\
The children stayed there & The children stayed in the garden. \\
\hline
\end{tabular}

\subsection{The Clause}

Because the clause is not often seen as a syntactic unit in its own right, its treatment in the books is shallow (Greater attention is paid to the sentence instead.) and characterised by inconsistencies. Nevertheless, some recognition is accorded to the clause in the form of definition. In EEL, a clause is defined as 'a group of words with a finite verb, forming part of the sentence' (p.80). Not only does this definition rule out non-finite clauses that do not independently constitute simple sentences, it says nothing about clause structure. SEP 1(p.126) appears to redress this shortcoming when it states that a clause is 'a group of words containing one subject and one predicate' (See GFE 1, p. 110).Apart from excluding imperative clauses which generally lack a subject, this description misrepresents the structure of the English clause. GFE 1 adds that a clause realises an element of sentence structure, forms a sentence on its own (e.g., 'A simple sentence is a clause', SEP1, p.26), and has subordinate/ dependent and main/ independent subclasses (EEL, p.80). Among the examples of subordinate clauses cited is the NMG with a rankshifted relative clause as qualifier, shown in its clause context and analysed into its elements of structure in [9a]-[9b] respectively.

$$
\mathrm{S} \quad \mathrm{P} \quad \mathrm{A}
$$

[19a] ||The landlord whose house was burgled | has reported | to the police || (EEL, p.81). 
$\begin{array}{lll}\text { M } & \mathrm{H} & \mathrm{Q}\end{array}$

[19b] |the landlord [[whose house was burgled] ]|

The absence of a clear-cut distinction between phrase and clause and the non-recognition of rankshifting due to model deficiency give rise to errors such as shown above. Finiteness as a distinguishing criterion for clause has been unsuccessful because it suggests wrongly that a clause has finite verbs whereas a phrase has non-finite verbs (EEL, pp.77 \& 80). These same factors also explain why subordinate clauses are misclassified into three, and each subtype is named after the word class that heads the group that ordinarily realises optional elements of clause structure as subject, complement or adjunct. Thus a clause that is rankshifted to function as subject or complement is called a noun clause; the one in adjunct function is known as an adverb(adverbial) clause, and that which functions as qualifier in the NMG or PRG structure is termed an adjective clause (cf. GFE 1, pp.110-114; EEL; pp.81-84). An example each will suffice.

[20]How Shola passed the examination beats the imagination of her teachers (EEL, p.81)

[21] We left when it became dark (GFE 1, p.112)

[22] Here is the book that our teacher recommended (GFE 1, p.112).

The awkwardness, incongruity and unsoundness of these descriptions are even more obvious in the examples. Not surprisingly, therefore, teachers and pupils alike confess that questions such as 'What grammatical name is given to this expression as used in the passage?' 'What is its function?' (EEL p.104) constitute the greatest nightmare candidates experience in the Senior School Certificate English Language Examination. Minor clauses attracted no mention even though they are a part of natural language structure.

That no existing syntactic model accurately analyses the three acts of language implies that would-be English teachers taught using them will be grossly deficient in their knowledge base of the syntactic structures of affirmative, interrogative, and imperative clauses. These incidentally are what the average language user encounters in varying degrees every day. So, it is shameful that students cannot describe their structures and therefore cannot formally distinguish them, one from the other. Outside differentiating them functionally as statements, questions and commands respectively, there is absolutely not much they can say concerning their syntactical properties. For example, they cannot recognise the absence of the subject in imperatives, possibility of multiple complements and adjuncts in affirmative clauses, and inversion of clause structure elements in interrogatives and some affirmatives. This situation further explains their near absence in the four books examined. Though EEL (pp.67-73) has something on 'questions', rightly described as 'interrogative sentences' and presented as 'questions asking for information' (non-polar) and 'simple questions requiring "yes" or "no" " (polar), the focus is on tag questions. GFE1 (p.67) merely lists them as 'kinds of sentences'.

\subsection{The Sentence}

The sentence is one of the most basic and oldest terms in linguistics; yet it is one of the most confusing and inaccurately defined, described and taught. The fact that there are over two hundred different definitions of the sentence (Fries, 1952) poses a number of descriptive problems itself. The revelation that existing syntactic models inaccurately represent the sentence throws up even greater challenges for English course books, topmost of which is sentence typology, which has capacity to impact both its definition and structure as the largest syntactic unit.

Four sets of sentence types are generally identifiable in the grammar. These are:

(i) simple, complex

(ii) simple, compound, complex

(iii) simple, compound, complex, compound-complex

(iv) simple, complex, compound, multiple.

Described as 'descriptive anarchy' arising from disagreement 'over the status and structure of the sentence' and a confusion of semantic complexity with syntactic complexity', only (ii) most accurately represents English sentence types. This is generate-able from the structural formula $\left(\beta^{0-n}\right) \alpha^{1-n}\left(\beta^{0-n}\right)$, which indicates that a sentence has obligatory and optional elements of structure and that the beta clause cannot on its own constitute a grammatical sentence (Adejare \& Adejare, 2006). According to Quirk et al. (1985), a 'simple sentence consists of a single independent clause', a compound sentence contains 'two or more COORDINATE clauses', and a complex sentence has 'one or more of its elements such as direct object or adverbial realized by a SUBORDINATE clause'. It is with the complex sentence that there are discrepancies regarding the structural formula, as simple sentences with subordinate clauses as adjunct or complement are listed as complex. What makes a sentence complex, and this point 
cannot be over-emphasised, is the presence of the subordinate clause as an optional element of sentence structure, not as an element of clause structure, where it serves subject, complement or adjunct of an independent clause or a simple sentence (Adejare, 2018).

Thus, even though all existing syntactic models reserve the same nomenclature for the largest syntactic unit sentence, there remain some descriptive problems as evident above. Consequently, sentence structure is not often taught even at the university level. If would-be English teachers and prospective textbook writers cannot accurately analyse sentence structure and cannot correctly distinguish simple, compound and complex sentences, one from the other, they would definitely have difficulty teaching what is correct. The sentence as presented in the books is here examined in terms of definitions, functional classification, formal classification (typology), descriptive statements, and structure.

\subsubsection{Definitions}

Two definitions of the sentence given are:

(i) '.A sentence is a group of words that form (sic) a statement, command, exclamation or question...It contains a subject and a verb...A sentence may contain one or more clauses or phrases.' (EEL, p.2)

(ii)' ...a sentence means a group of words that makes complete sense when spoken or written...a sentence has a subject and a verb.... a sentence is usually divided into a subject and a predicate.'.(GFE 1, p.67ff)

Notice that, apart from being notional, structural and functional at once, the definitions do not clearly distinguish the sentence from the clause in terms of structural elements and constituents. Moreover, phrases, wrongly used as a co-terminus for groups, do not realise sentence structure; it is clauses that enter directly into the structure of the sentence. These will undoubtedly leave the pupils confused.

\subsubsection{Functional Classification}

Since the clause is sometimes not recognised as a syntactic unit in its own right, and this is a grave descriptive error with consequences for language teaching and learning as has been pointed out, the functional classification of clauses into affirmative, interrogative, and imperative (Adejare \& Adejare, 2006) is presented in GFE1 (p.67) as 'kinds of sentences'. No formal statement outside semantic descriptions of each subtype is offered. The sentential illustrations are generally appropriate except for those of imperative clauses, where 67 per cent (4 out of 6) are syntactically interrogative clauses. An example is 'May I make use of your biro?', marked 'request'. Though VBGs marked for imperative mood typically express commands, requests and directives, they are finite base form verbs and do not occur with an auxiliary except in negation (e.g., GFE's 'Don't make a noise'). More significantly, they do not occur in subordinate clauses and interrogative clauses because they are performative (Palmer, 1987, 2001; Halliday \&Matthiessen, 2004). It is descriptively inaccurate therefore to cite interrogative clauses as imperative clauses.

\subsubsection{Formal Classification of the Sentence}

When would-be teachers are fed the wrong notion that English has four structurally distinct types of sentence instead of three, it becomes inevitable that pupils learning English would be fed the same pot of descriptive fallacies through their course books. Only SEP1 correctly recognises three (simple, compound and complex); the rest identify four.

(a) The Simple Sentence

EEL (p.6) and GFE1 (p.68) define the simple sentence notionally (one idea), differing only in emphasis on constituents (an independent clause), and structure (one subject and one predicate), respectively. All six examples cited, including EEL's 'She found Olu sitting on a chair', are correct. Although the inadequate 'subject and predicate' also recur in SEP 1's (p.125) strictly syntactic definition, the book specifies each element's constituents, notes that 'verb' is obligatory in the predicate while objects, complements and adjuncts are optional. It even provides a diagrammed example, revealing the combined influence of Traditional Grammar and TG. 


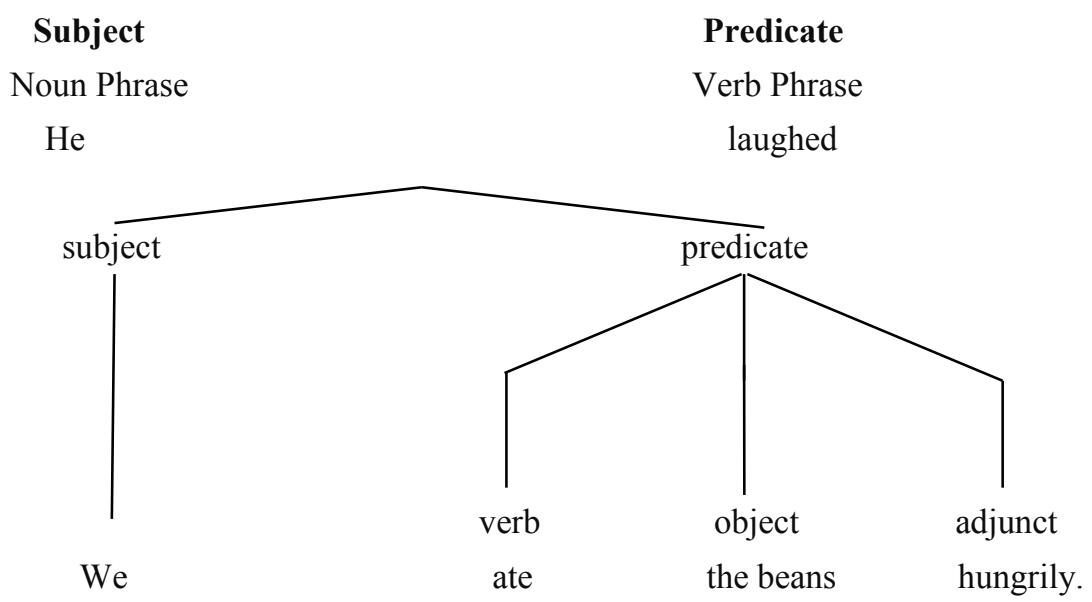

\section{(b)The Compound Sentence}

No ill-description of the compound sentence is seen. The books correctly describe the compound sentence as one comprising two or more independent clauses joined by a coordinating conjunction. The accompanying examples are accurate, but none has more than two clauses, e.g.

[24]||( $\alpha$ )The woman walked into the room $\|$ and $\|(\alpha)$ found Olu sitting on a chair.|| (EEL,p.6)

(c)The Complex Sentence

The most confusion seems to lie with the complex sentence as already seen. The books recognise and correctly define the complex sentence as one consisting of one independent and one dependent clause. SEP 1 even shows how a complex sentence can be formed from two simple sentences by simply adding an appropriate subordinating conjunction. However, only two of the five examples cited are syntactically complex sentences in the sense that they have two separately occurring clauses of unequal grammatical status. The sentences are analysed as follows:

[25]||( $\alpha$ )Obi rescued the goat, ||( $\beta$ )although| the snake had got very close to it||| (SEP1, p.126)

[26] |||( $\alpha$ )The teacher | flogged| him || ( $\beta$ ) because| he jumped the fence||(EEL, p.6)

The rest are simple sentences erroneously tagged complex sentences due to failure to acknowledge rankshifting, a natural language phenomenon wherein a clause gets embedded within the structure of another clause as an element of that clause's structure. In the examples analysed below to show their correct syntactic status as simple sentences, the rankshifted clauses (marked) are either adjuncts or qualifiers in the structure of NMGs functioning as complements.

$$
\mathrm{S} \quad \mathrm{P} \quad \mathrm{C} \quad \mathrm{A}
$$

[27] ||We |entered |the classroom |[[after the biology teacher had left]]|| (GFE1,p.249)

$$
\mathrm{S} \quad \mathrm{P} \quad \mathrm{C}
$$

[28]||I |know |the year [[when Solomon completed his studies]].|| (GFE1, p.68)

$$
\mathrm{S} \quad \mathrm{P} \quad \mathrm{C}
$$

[29]||This | is |the girl [[who danced very well at the party]]|| (EEL, p.6)

$$
\mathrm{S} \quad \mathrm{P} \quad \mathrm{C}
$$

[30] ||This |is |the house [[that Olabisi built.]]\| (GFE1, p.249)

A five-item practice exercise on the complex sentence requiring pupils to decide which clause is dependent or independent contains only two complex sentences (e.g., [31]); the rest are simple sentences manifesting rankshifting (e.g., [32]).

$[31]||(\alpha)$ We are requesting donations from the mosque, $\|(\beta)$ which needs painting $\|$ (SEP1, p.132).

$$
\mathrm{S} \quad \mathrm{P} \quad \mathrm{C}
$$


[32]||Mohammed |preached |[[that there is only one God]]. || (SEP1, p.132).

The non-recognition of rankshifting also leads to the incorrect description of reported speech as a variant of the complex sentence. Here is one example, accurately analysed.

$$
\mathrm{S} \quad \mathrm{P} \quad \mathrm{C}
$$

[33] ||The spokeswoman |said |[[that the company buys Nigerian oil]]|| (SEP1, p.143).

(d)The 'Compound-Complex' Sentence?

The notion of 'compound-complex' sentence is descriptively anomalous, vague and imprecise. It does not exist and does not have a place in the syntactic structure of English. A sentence is structurally simple, compound or complex as already seen; it cannot be both compound and complex at the same time. The $\left(\beta^{(0-n)}\right) \alpha^{(1-n)}\left(\beta^{(0-n)}\right)$ structural formula derived for the sentence implies that a complex sentence can have any number of alpha and beta clauses. So, EEL's (p.7) definition of the 'compound-complex' sentence as 'a sentence with at least two independent clauses and at least one dependent clause' (Ofuya, 1987) only illustrates a syntactic variant of the complex sentence. Consequently, the examples are either those of complex sentences or compound sentences, as [34] and [35], correctly analysed below, respectively show.

[34]||( $\beta)$ While the teacher was teaching, || $(\alpha)$ the students shouted at him||and $\|(\alpha)$ laughed at him.|||

(GFE1, p.68)

[35] |||( $\alpha$ )Your creditor came yesterday[[when you were not at home ]], ||but $\|(\alpha)$ I was able to pay him. |||

(EEL, p.7)

\subsubsection{Descriptive Statements}

An attempt at distinguishing between compound sentences and complex sentences (GFE 1, p.249) further exposes the difficulty with correctly identifying and illustrating the complex sentence. In the pairs of sentences analysed below, the second, ostensibly illustrating the complex sentence, are actually simple sentences with rankshifted clauses at the $\mathrm{Q}$ position of a $\mathrm{NMG}$ at $\mathrm{C}$ and at A respectively.

$$
+
$$

[36a] $\|(\alpha)$ The lady entered the sitting room $\|$ and $\|(\alpha)$ smiled at me.|\|

$$
\text { S P C }
$$

[36b] ||This | is| the house [[that Olabisi built]]\|

$$
+
$$

[37a] $\|(\alpha)$ The dog barked at me $\|$ and $\|(\alpha)$ ran into the kitchen $\|$

$$
\begin{array}{llll}
\mathrm{S} & \mathrm{P} & \mathrm{A} 1 & \mathrm{~A} 2
\end{array}
$$

[37b] ||The dog| barked |at me |[[while I was cooking in the kitchen]]\|

Two other factors readily explain the descriptive errors in the examples so far examined: There is ignorance about elements of sentence structure consisting of an obligatory independent (alpha) clause and an optional dependent (beta) clause. There is also confusion of semantic complexity with syntactic complexity, where the subject, complement or adjunct contains a lot of information (e.g., [29] above).

The apparent lack of distinction between sentence and clause in respect of elements of structure alluded to earlier means that elements of clause structure are presented as elements of sentence structure. This is taken up next.

\subsubsection{Sentence Structure or Clause Structure}

Following NTG, EEL (p.2) declares that a 'sentence comprises five units' called 'elements of sentence', identifies them as subject, verb, complement, object and adverbial (SVCOA), and adds that S and V are 'compulsory elements'. Although the designation of $\mathrm{S}$ and $\mathrm{V}$ as 'compulsory elements' is a tacit recognition of optionality of elements of structure, assigning obligatory status to $\mathrm{S}$ means that pupils cannot use the $\mathrm{S}+\mathrm{V}+\mathrm{O}+\mathrm{C}+\mathrm{A}$ formula to accurately construct imperative clauses without subjects. Table 4 illustrates. 
Table 4. Elements of Clause Structure?

\begin{tabular}{|c|c|c|c|c|c|c|}
\hline & \multirow[b]{2}{*}{ Subject } & \multirow[b]{2}{*}{ Verb } & \multicolumn{2}{|c|}{ Object } & \multirow[b]{2}{*}{ Complement } & \multirow[b]{2}{*}{ Adverbial } \\
\hline & & & Indirect & Direct & & \\
\hline 1 & Jesus & wept & & & & \\
\hline 2 & Kunle & gave & the girl & an orange & & last week \\
\hline 3 & The girl & is & a good student & & & \\
\hline 4 & The small girl & grew & & & happier & every day \\
\hline 5 & They & made & him & the chairman & & every year \\
\hline
\end{tabular}

While explicating each element of structure, noticeable model confusion sets in when EEL (p.3) reverts to Traditional Grammar's subject and predicate thus:

Table 5. Traditional Grammar's Elements of Sentence Structure

\begin{tabular}{ll}
\hline Subject & Predicate \\
\hline Jesus & Wept \\
Kunle & gave the girl an orange \\
The girl & is a good student \\
The small & grew happier every day \\
They & made him a chairmen every year \\
\hline
\end{tabular}

The question that arises is this: Which of these two inaccurate descriptive alternatives are teachers and pupils meant to follow in their analysis of clause structure? (See [23] above.)) The recourse to Traditional Grammar could not have been motivated by eclecticism. It is at best the product of descriptive inconsistency or ignorance or both, and this is where the challenge lies.

Based on NTG's structural formula, GFE 3 (p.139) provides what may be considered a mnemonic in [38] below. Preceded by the instruction 'For a thorough knowledge of the sentence, you should always remember the following' (p.138), it significantly includes a polar interrogative clause and clauses with multiple complements wrongly labelled objects.

[38]
(a) $\mathrm{S}+\mathrm{V}$
She /sings
(b) $\mathrm{S}+\mathrm{V}+\mathrm{O}$
She /sings /songs
(c) $\mathrm{S}+\mathrm{V}+\mathrm{A}$
She /sings/well
(d) $\mathrm{S}+\mathrm{V}+\mathrm{C}$
She/ is /beautiful
(e) $\mathrm{S}+\mathrm{V}+\mathrm{O}+\mathrm{A}$
She /sings /songs/well
(f) $\mathrm{S}+\mathrm{V}+\mathrm{O}+\mathrm{C}$
She /called /him /a fool
(g) $\mathrm{S}+\mathrm{V}+\mathrm{O}+\mathrm{O}$
She /gave/ me /some money
(h) $\mathrm{S}+\mathrm{V}+\mathrm{Oi}+\mathrm{Od}+\mathrm{A}$
She /gave/ me /some money last week
(i) $\mathrm{V}+\mathrm{S}+\mathrm{V}+\mathrm{O}+\mathrm{A}$
Did /she /see / him /yesterday?

Two examples cited in SEP1 (p.114) depict mobility and multiplicity of adjunct('Eventually she found the money on the table near the clock'), which is at variance with the chosen model, but which reinforces the argument that the models do not mirror natural language structure. It also correctly distinguishes $\mathrm{A}$ as an element of structure from the items that realise it thus: ' $\ldots$ an adjunct may be a one-word adverb or it may be a phrase. It may alternatively be a clause'. If rankshifted clauses are understood as capable of functioning as an adjunct or any other optional element of clause structure, why are they always wrongly taken as sentence constituents? Again, the culprit lies in not according 
the clause its due recognition as a syntactic unit. This leads to its conflation with the sentence. It also explains why the complex sentence is the most incorrectly described and illustrated.

The inaccuracy of phrase as a descriptive term caused errors in the exemplification of the adjunct, as joyfully and with great joy, respectively H-Type ADG and HQ-Type PRG, are labelled adverb and phrase respectively(See Table 3 above).

[39] 'She told me the news joyfully.

[40] 'She told me the news with great joy'

The same confusion between a unit's constituents and its elements of structure is evident in SEP1's (p.22) description of the NMG. It is clear from Table 6 below that these are structural variants and their realisations: The H-Type NMG is realised by proper nouns or personal pronouns while the MH-Type NMG has a determiner or a determiner and an epithet as $\mathrm{M}$ and a common noun as $\mathrm{H}$.

Table 6. Constituents and Elements of the NMG Structure

\begin{tabular}{ll}
\hline \multicolumn{1}{c}{ Structure } & Example \\
\hline Noun & Arin \\
determiner + noun & Their father \\
determiner+ adjective + noun & A closely-knit family \\
Pronoun & They \\
\hline
\end{tabular}

\subsection{Summary of Observations}

The foregoing shows that the syntactic components of the English course books recommended for senior secondary school pupils in Nigeria are predicated on descriptively inadequate syntactic models. The challenges posed are overwhelmingly manifest, spanning the three largest syntactic units (sentence, clause and group) and reflecting in diverse ways. Some of these are inconsistency in the choice of model, apparent lack of uniformity in, and consensus on, the number and identity of syntactic units, terminological confusion, non-recognition and inaccurate identification of given units, and typological inexactness. Others are incorrect definitions of basic terms, descriptively incorrect and inappropriate examples, confusion between constituents of structure and elements of structure, lack of a clear-cut distinction between phrase and clause on the one hand, and between clause and sentence on the other hand, and inaccurate description of structure. The use of syntactic models that do not promote natural language is responsible for the shortcomings found in the books examined. This is totally unacceptable in view of the place of course books in the teaching and learning of English in Nigeria. It creates doubts whether children taught entirely with these books can acquire and use Standard English, given the level of inaccuracy of the descriptions therein. What is most gratifying, however, is that the average Nigerian learner of English is exposed to multiple sources of good usage outside the course books and the English lessons.

One motivation for this study is the absence of any known work on course book evaluation devoted to the syntactic models that inform their grammatical contents. Previous studies have tended to be check-list based as earlier noted, and the grammar aspects are pedagogically oriented. One such study is Makundan et al.'s (2011), whose check-list includes whether or not the grammar is contextualised and whether it is explicitly introduced or implicitly reworked. It significantly excludes any item on syntactic models, no matter how remotely related. It is this lack of known precedents that makes comparison of this study's outcomes with others difficult.

\section{Conclusion}

The implications of the findings for language education in Nigeria can now be highlighted as concluding remarks.

It is evident from what has been seen in this study that linguistics has to be focused on describing the language that people actually use. This is where Chomsky's (1976) admission of a 'near-total failure...in developing a scientific theory...for natural use of language' comes in. To enhance language education natural language structure has to be accurately described and taught, rather than the linguist inventing and describing their own language, which is fraught with danger. Even in L1 situations like the USA, the fact that linguists do not describe the actual language that people use gives rise to people not wanting to teach or be taught grammar. This is evidenced by the recent debate on diagramming sentences, where it is argued that the art 'teaches nothing beyond the ability to draw'. Traced 
to Professors Alonza Reeds and Brainerd Kellog who, in their 1877 book titled Higher Lessons in English, had reckoned that students would learn to structure sentences better if presented to them as graphics (Summers, 2014), diagramming sentences is not an entirely mechanical and useless technique as painted. On the contrary, tree diagrams are very useful for teaching grammatical structure provided they are accurately modelling the structure of natural language.

In an L2 situation, there is no option to grammar teaching because there is no speech community akin to what the L1 learner has. Besides, the L2 learner does not possess an intuitive knowledge of the structure of the language and so relies on their teachers and the English course books, which themselves depict the inaccuracies of the syntactic models that inform them, as this work has shown. This is why accurate description and teaching of the actual language that people use become imperative. When we begin to focus on what people actually say, the type of situation that led to Hirtle's (1990) observation 'that the particular model or set of rules with which they (students) have been indoctrinated springs fully armed from the brain ... of the ideal linguist' will stop. It is therefore imperative that the L2 learner be taught accurate description of English structures based on an accurate syntactic model such as the emerging Natural Language Linguistics model.

This paper has shown, through a detailed examination of four selected English course books used in Nigeria's senior secondary schools, that existing syntactic models pose great challenges for English language education because they do not mirror natural language. The books are faulted on several grounds, including inaccurate descriptive statements, wrong examples, misclassification of syntactic units, and poor definitions. It would therefore seem that there is no alternative to a syntactic model that most accurately describes the actual language that real human beings use in their everyday communication tasks. Since what obtains now amounts to treating the symptoms of a disease and leaving the causative factors unexplored, it would be desirable for linguists to embrace what is right for all. This would then provide the assurance that the English course books which teachers and pupils so heavily rely upon would be free of fundamental errors, teachers and authors would be more knowledgeable, and pupils would be more proficient users of the language.

\section{References}

Abe, E. A. (1984). The language arts programmes in teacher education at the undergraduate level: Need and direction for a reappraisal. In R. Freeman \& M. Jubril (Eds.), English language studies in Nigerian higher education (pp.167-175). London: The British Council \& the Nigeria English Studies Association.

Adejare, O. (1984). Towards a language-centred English degree programme. In R. Freeman \& M. Jubril (Eds.), English language studies in Nigerian higher education (pp.187-192). London: The British Council \& the Nigeria English Studies Association.

Adejare, O. (1990). Elements of the English clause structure. Savannah: A Journal of the Environmental and Social Sciences, 11(2), 103-115.

Adejare, O. (Forthcoming). Natural language linguistics: Text, form and situation.

Adejare, R A., \& Adejare, O. (2006). Tertiary English grammar (2nd ed.). Lagos: DIFAMO Books.

Adejare, R. A. (2003). The English teacher education programmes of Nigerian universities. Journal of Arts and Social Sciences, 6(1), 168-188.

Adejare, R. A. (2018). Sentence pattern and usage in Nigeria's 2015 presidential debate. Advances in Language and Literary Studies, 9(4), 117-137. http://dx.doi.org/10.7575/aiac.alls.v.9n. 4p1117

Bamgbose, A. (1991). Language and the nation: The language question in Sub-Saharan Africa. Edinburgh: Edinburgh University Press.

Chomsky, N. (1965). Aspects of the theory of syntax. Cambridge: Massachusetts: The MIT Press. https://doi.org/10.21236/AD0616323

Chomsky, N. (1976). Reflections on language. London: Temple Smith.

Christophersen, P., \& Sandved, O. (1969). An advanced English grammar. London: Macmillan.

Firth, J. R. (1957). Papers in linguistics: 1934-1951. London: Oxford University Press.

Fries, C. C. (1952). The structure of English. New York: Longman.

Grant, N. J. H., Nnamonu, S., \& Jowitt, D. (2011). Senior English project for secondary schools: Students book 
1.London: Longman, Pearson Education Limited.

Halliday, M. A. K. (1961). Categories of the theory of grammar. Word, 17(3), 241-92. https://doi.org/10.1080/00437956.1961.11659756

Halliday, M. A. K. (1985). An introduction to functional grammar. London: Edward Arnold.

Halliday, M. A. K., \& Matthiessen, C. M. I. M. (2004). An introduction to functional grammar. London: Arnold.

Halliday, M. A. K., Mclntosh, A., \& Strevens, P. (1964). The linguistic sciences and language teaching. London: Longman.

Harris, R. (1990). The integrationist critique of orthodox linguistics. In M.P. Jordan (Ed.), The Sixteenth LACUS Forum 1989 (pp 63-77). Illinois: LACUS. The Linguistic Association of Canada and the United States.

Hirtle, W. (1990). The rest of the iceberg: Exploring the operational dimension of language. In M P. Jordan (Ed.), The Sixteenth LACUS Forum 1989 (pp5-15). Illinois: LACUS, The Linguistic Association of Canada and the United States.

Jespersen, O. (1933). Essentials of English grammar. London: Allen \& Unwin.

Latilo, T. A., \& Beckley, A. T. (2008). Essential English language for senior secondary schools (2nd ed.). Lagos: Tonad Publishers.

Lopez-Medina, B. (2016). Developing a CLIL textbook evaluation checklist. Latin American journal of content \& integrated learning (LACLIL), 9(1), 159-179. https://doi.org/10.5294/lacli1.2016.9.1.7

Makundan, J., Nimehchisalem. V., \& Hajimohammadi, R. (2011). Developing an English language textbook evaluation checklist. Contemporary Issues in Education Research (CIER), 4(6), 21-28. https://doi.org/10.19030/cier.v4i6.383

Mebele, K., \& Omodara, F. (2006). Goodbye to failure in English for senior secondary schools: Students' book 3 (Revised edition). Lagos: Treasure Publishers Limited.

Mebele, K., \& Omodara, F. (2018). Goodbye to failure in English for senior secondary schools: Students' book 1 (3rd ed.). Lagos: Treasure Publishers Limited.

Mohmed, A. (1976). What? How? How much? Thoughts on university English in Nigeria. English Language Teaching Journal (ELT), 31(1), 52-56. https://doi.org/10.1093/elt/XXXI.1.52

Ofuya, V. A. (1987). A functional English grammar in a second language situation. In E. A. Adegbija (Ed.), Effective study skills and use of English (pp.53-156). Ilorin: The General Studies and National Awareness Division, University of Ilorin.

Palmer, F. R. (1987). The English verb (2nd ed.). London: Longman.

Palmer, F.R. (2001). Mood and modality. Cambridge: Cambridge: University Press. https://doi.org/10.1017/CBO9781139167178

Quirk, R., Greenbaum, S., Leech, G., \& Svartvik, J. (1985). A comprehensive grammar of the English language. London: Longman.

Radford, A. (2004). English syntax: An introduction. Cambridge: Cambridge University Press. https://doi.org/10.1017/CBO9780511841675

Saussure, F. de (1916). A course in general linguistics. In Wade Baskin (Ed.), Charles Bally and Albert Sechehaye. Intro. Jonathan Culler. Glasgow: Fontana/Collins, 1974.

Summers, J. (2014). NPR.ORG A picture of language: The fading art of diagramming sentences. Retrieved August 2014 at 18:48 fromwww.facebook.com/122624624418852/posts/900478133300160/22

Thuy-Minh, N. (2015). Textbook evaluation: The case of English textbooks currently in use in Vietnam's upper secondary schools. Unpublished research report. Singapore: RELC, SEAMEO REGIONA LANGUAGE CENTRE 2007, pp.1-74. https://www.doi.10.13140/RG2.1.1219.2165

\section{Acknowledgement}

Inspiration for this paper came from an informal but extensive discussion I had with Professor Oluwole Adejare on linguistic theory on 10 November 2018 in Lagos, Nigeria. While his comments on the initial draft were quite useful in structuring the arguments of the discourse, I take full responsibility for the outcome. 